\title{
HEAT STORAGE IN THE EASTERN MEDITERRANEAN
}

\author{
By
}

IBRAHIM A. MAIYZA

National Institute of of Oceanography and Fisheries,

Kayet-Bay, Alexandria, Egypt

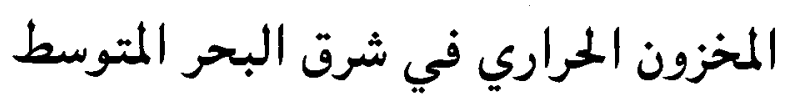

إبر اهيم أمين أحمل معيزة

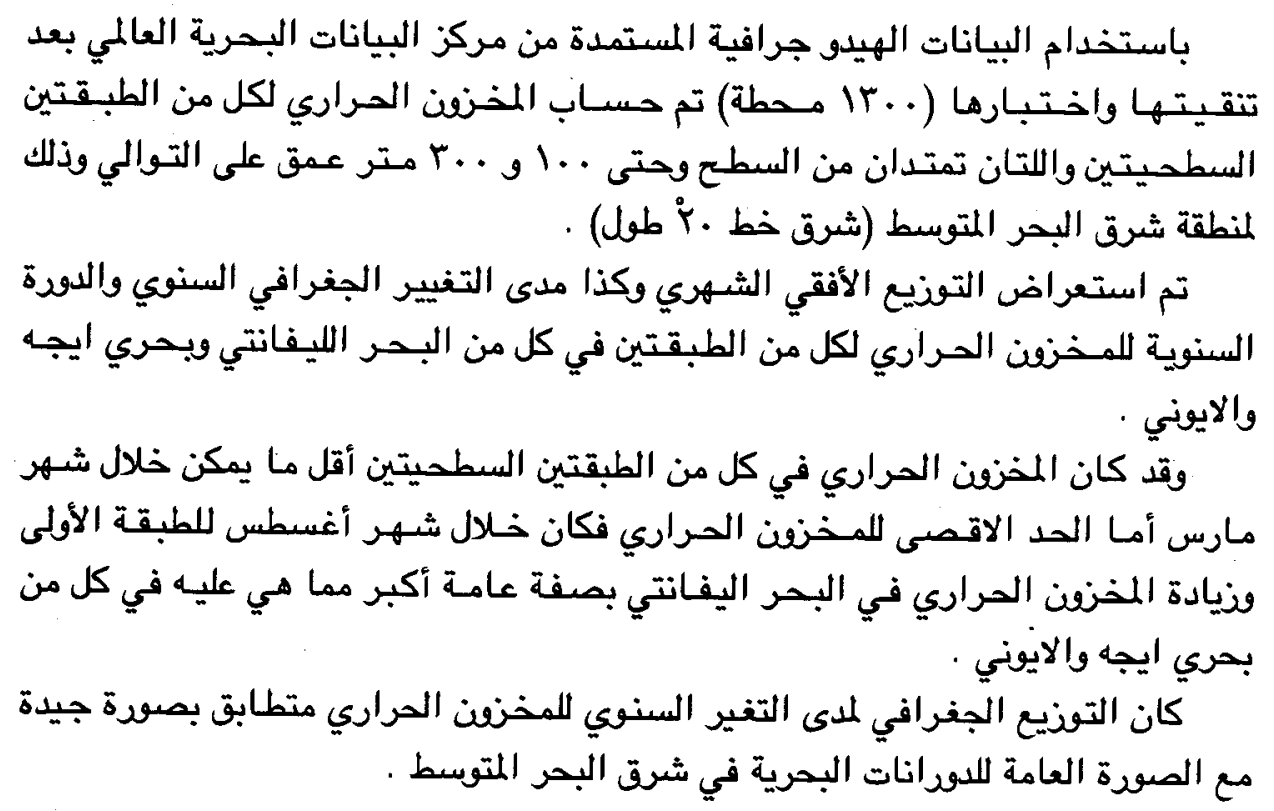

Key Words: Heat Storage, Mediterranean, Levantine

\section{ABSTRACT}

Results of the monthly climatological fields of heat storage for the Eastern Mediterranean are presented. The zonal annual trend of monthly mean heat storage in the Levantine, Aegean and Ionian Seas are shown as well as the horizontal distribution of the amplitude of the annual signal. These distributions are presented for the $0-100$ and $0-300 \mathrm{~m}$ layers to describe the global geographic characteristics of the annual cycle of heat storage for the Mediterranean Sea east of Meridian $20^{\circ} \mathrm{E}$.

The hydrographic data used to estimate heat storage are the 0.5 degree spaced objectively analyzed field of temperature, which are based on about 1300 hydrographic stations retrieved from the NODC-Washington-DC data file, up to 1985 .

For both layers considered, the minimum heat storage was observed in March, whereas the maximum occurred in August for the upper 0-100 m layer and in September for the 0-300 m layer. The amount of heat stored and its duration are generally higher in the Levantine Basin. The geographical distribution of the amplitude of the annual signal is in good agreement with some general circulation schemes of the area under study.

\section{INTRODUCTION}

The heat storage in the oceanic surface layers may be subject to considerable variability in space and time. In spite of the fact that, the heat storage plays an essential role in the dynamic of the ocean, few studies have considered this subject in the Mediterranean.

Said (1985) studied the region of formation of the intermediate water mass in the Mediterranean Sea depending upon the deviation of the heat budget from the long-term average of the cold period of the year. He concluded that, the 
formation of this water mass takes place in the Levantine Sea excluding its southern and extreme eastern parts.

Picco (1990) studied the heat storage in the upper 0-100 and $0-300 \mathrm{~m}$ layers in the western Mediterranean. He discussed the annual trend of the monthly mean heat storage and the geographic distribution of the amplitude of the annual signal, which was in good agreement with the general circulation pattern. He assumed that, the water density $(\rho)$ and the specific heat capacity $\left(C_{p}\right)$ were constant, similar to the work of Levitus (1984), who had studied the rate of change of heat storage in the World Ocean. $\rho$ and $C_{p}$, which are both a function of temperature and salinity, must be taken into consideration in the relatively active mediterranean water masses

This paper presents the monthly geographic distribution of heat storage; the annual trend of the monthly mean heat storage in the Levantine, Aegean and Ionian Seas: and horizontal distribution of the amplitude of the annual signal, in the upper 100 and $300 \mathrm{~m}$ layers in the Eastern Mediterranean Sea.

Verification of the ability of sea or sea - atmosphere circulation model to simulate the real condition should, in part, be based on a comparison of the geographic distribution of the heat storage (or the rate of its variability). Diagnostic studies on regional scales may require the geographic distribution of the storage. The purpose of the present paper is to provide a quantitative description of the heat storage based on historical hydrographic data.

\section{STUDY AREA, DATA AND ANALYSIS}

The hydrographic data were retrieved from NODC, the WDC-A data file. It is made up of about 1300 objectively tested TS profiles for the eastern Mediterranean, regardless of the year of observation. The data were selected with a resolution of $0.5^{\circ}$ latitude and longitude square to obtain monthly mean profiles. Vertical resolution is that of the standard depths. Heat storage was calculated for the upper 100 and $300 \mathrm{~m}$ layers for the Mediterranean, east of meridian $20^{\circ} \mathrm{E}$. The area if study contains the Levantine and Aegean Seas and the eastern part of the Ionian Sea.

The first layer includes the Mediterranean surface and Atlantic subsurface water masses. The upper $300 \mathrm{~m}$ layer contain the upper part of the Intermediate layer as well.

Monthly heat storage $(\mathrm{H})$ in $\mathrm{J} / \mathrm{m}^{2}$ has been estimated using the following relation:

$$
H=1 / 8 \Sigma\left(C_{p i}+C_{p i+1}\right)\left(\rho_{i}+\rho_{i+1}\right)\left(T_{i}+T_{i+1}\right)\left(Z_{i+1}-Z_{i}\right)
$$

where:

$\mathrm{C}_{\mathrm{pi}}$ : specific heat capacity in $\mathrm{J} / \mathrm{kg}^{\circ} \mathrm{K}$,

$\rho_{\mathrm{i}}$ : water density,

$\mathrm{T}_{\mathrm{i}}$ : water temperature,

$Z_{\mathrm{i}}$ : level depth,

Subscript (i) refers to the $\mathrm{i}^{\text {th }}$ level. 1972):

$$
\begin{aligned}
\mathrm{C}_{\mathrm{pi}} & =4186\left[1.0049-0.001621 \mathrm{~S}_{\mathrm{i}}+\left(3.5261 \mathrm{E}-6 \mathrm{~S}_{\mathrm{i}}^{2}\right)\right. \\
& -\left\{\left(3.2506-0.14795 \mathrm{~S}_{\mathrm{i}}+7.7765 \mathrm{E}-4 \mathrm{~S}_{\mathrm{i}}^{2}\right)^{*} \mathrm{E}-4 \mathrm{~T}_{\mathrm{i}}\right\} \\
& \left.+\left\{\left(3.8013-0.12084 \mathrm{~S}_{\mathrm{i}}+6.121 \mathrm{E}-4 \mathrm{~S}_{\mathrm{i}}\right)^{*} \mathrm{E}^{-6} \mathrm{~T}_{\mathrm{i}}^{2}\right\}\right]
\end{aligned}
$$

HORIZONTAL DISTRIBUTION OF HEAT STORAGE:

The monthly geographical distribution of heat storage in the upper 100 and $300 \mathrm{~m}$ layers are illustrated in figure $(1, \mathrm{a}-\mathrm{d})$. The monthly extreme values of heat storage in the area under study for the two layers are shown in Table 1.

The lowest values of heat storage are observed in the northern Aegean Sea, whereas the highest occur along the southern and eastern boundary of the Levantine Basin (Fig. 1). The pattern of minima and maxima in heat storage values depends mainly upon their latitude.

The increasing heat storage value eastward along the African coast, and to some extent continuing northward along the Asian boundary may result from cyclonic motion associated with the north African current in the Levantine basin (Grillaki \& Piacsek, 1985). This current would advect the surface layer of high heat storage in this direction.

For both the upper 100 and $300 \mathrm{~m}$ layers, minimum heat storage values were observed in March (late winter season). Maxima occurred in August for the upper $100 \mathrm{~m}$ layer and in September for the 0-300 m layer (Table 1).

It should be mentioned that, in the northern Levantine Sea, between Crete and Cyprus islands, heat storage is lower year round. This region contains the Rhodes gyre, in which vertical convection may reach more than $300 \mathrm{~m}$ deep, and in which the formation of the intermediate water mass takes place (Hopkins, 1983). The formation of such layer may take place over all the Levantine basin in some cold winters, except in its southern parts (Said, 1985). Within this area, the heat is distributed over a considerably thicker layer. This results in a region of considerably lower heat storage.

Table 1.

Monthly extreme heat storage (in $10^{9} \mathrm{~J} / \mathrm{m}^{2}$ ) values in the upper 100 and $300 \mathrm{~m}$ layers

\begin{tabular}{lllll}
\hline Month & $\begin{array}{l}\text { Upper } 100 \\
\text { Min. }\end{array}$ & $\begin{array}{l}\text { m layer } \\
\text { Max. }\end{array}$ & $\begin{array}{l}\text { Upper } 300 \\
\text { Min. }\end{array}$ & $\begin{array}{l}\text { m layer } \\
\text { Max. }\end{array}$ \\
\hline Jan. & 5.4 & 7.5 & 17.8 & 20.8 \\
Feb. & 5.9 & 7.2 & 17.8 & 21.1 \\
Mar. & $5.1^{*}$ & $7.0^{*}$ & $16.7^{*}$ & $20.6^{*}$ \\
Apr. & 6.0 & 7.2 & 17.7 & 20.9 \\
May & 6.0 & 7.9 & 17.1 & 21.8 \\
June & 6.1 & 8.5 & 18.1 & 22.0 \\
July & 6.5 & 9.2 & 18.7 & 22.7 \\
Aug. & $7.1^{*}$ & $9.8 *$ & 18.0 & 22.9 \\
Sep. & 7.0 & 9.4 & $19.3 *$ & $23.7^{*}$ \\
Oct. & 6.9 & 9.4 & 17.6 & 22.1 \\
Nov. & 6.4 & 9.4 & 17.6 & 22.2 \\
Dec. & 6.2 & 8.5 & 18.0 & 22.2 \\
& & & &
\end{tabular}

* Indicate the maximum and minimum annual values. 


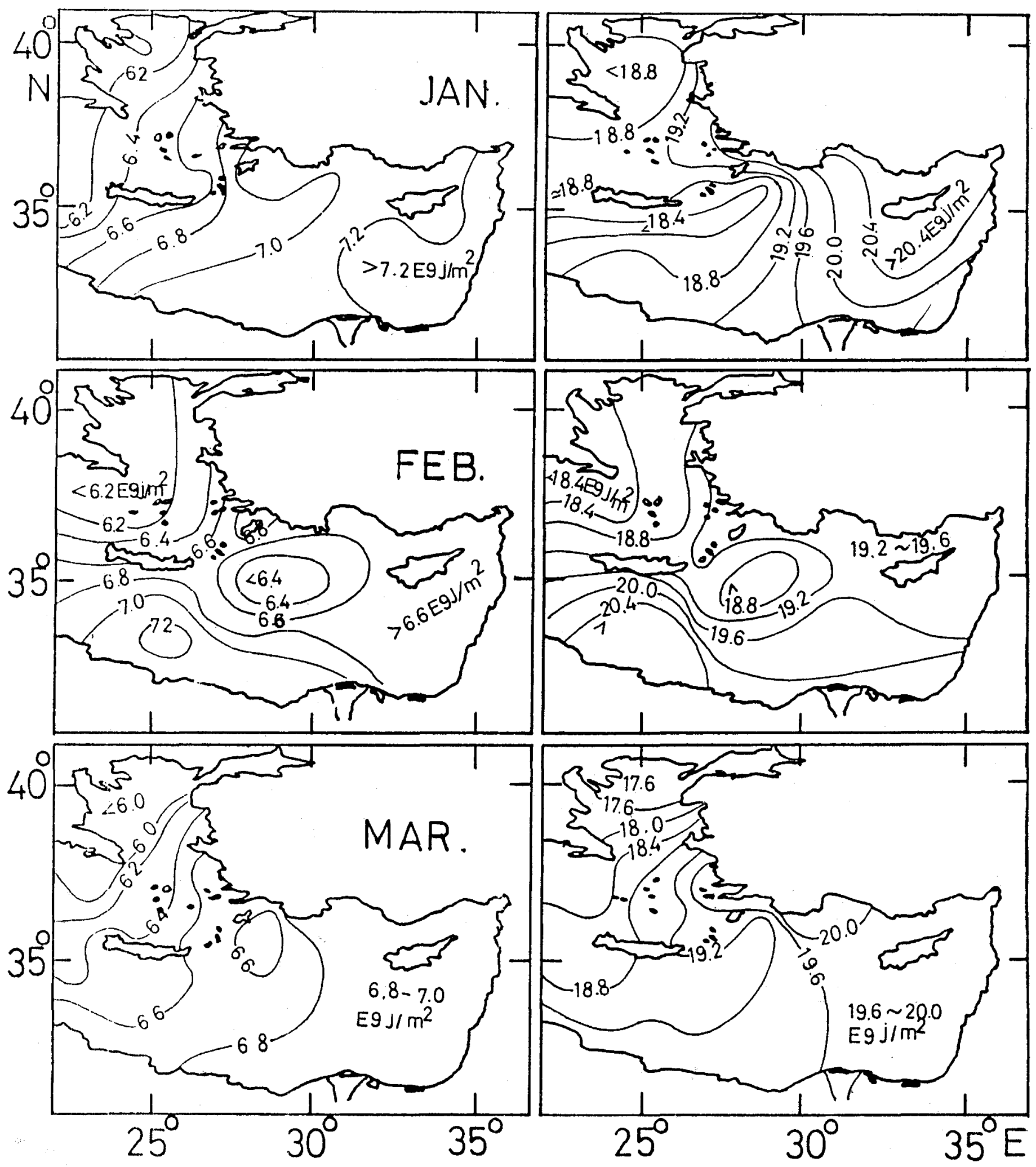

Fig. 1.a. Monthly distribution of heat storage in the upper 100m (Left panel) and $300 \mathrm{~m}$ (Right panel) layers in Winter. 

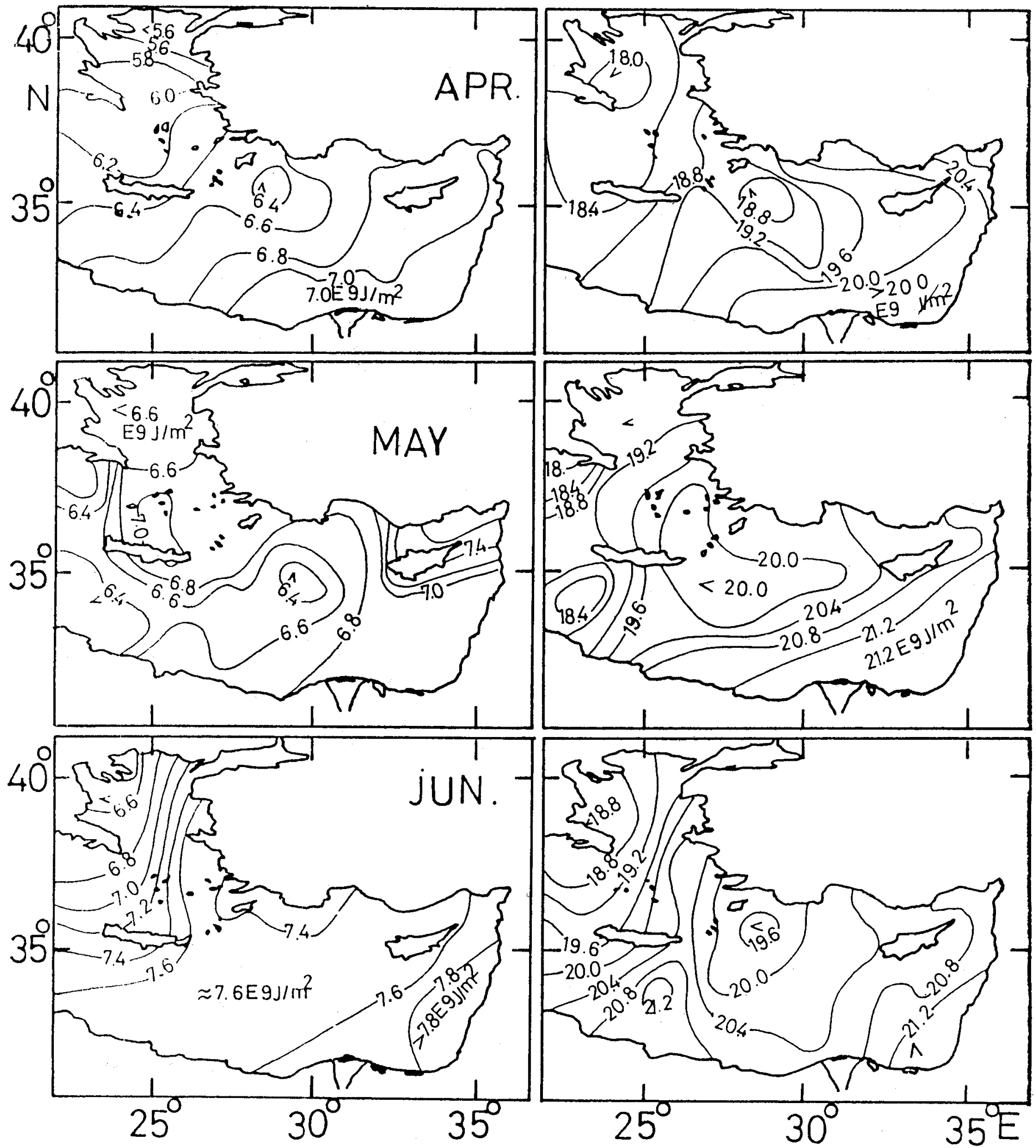

Fig. 1.b. Monthly distribution of heat storage in the upper $100 \mathrm{~m}$ (Left panel) and $300 \mathrm{~m}$ (Right panel) layers in Spring. 

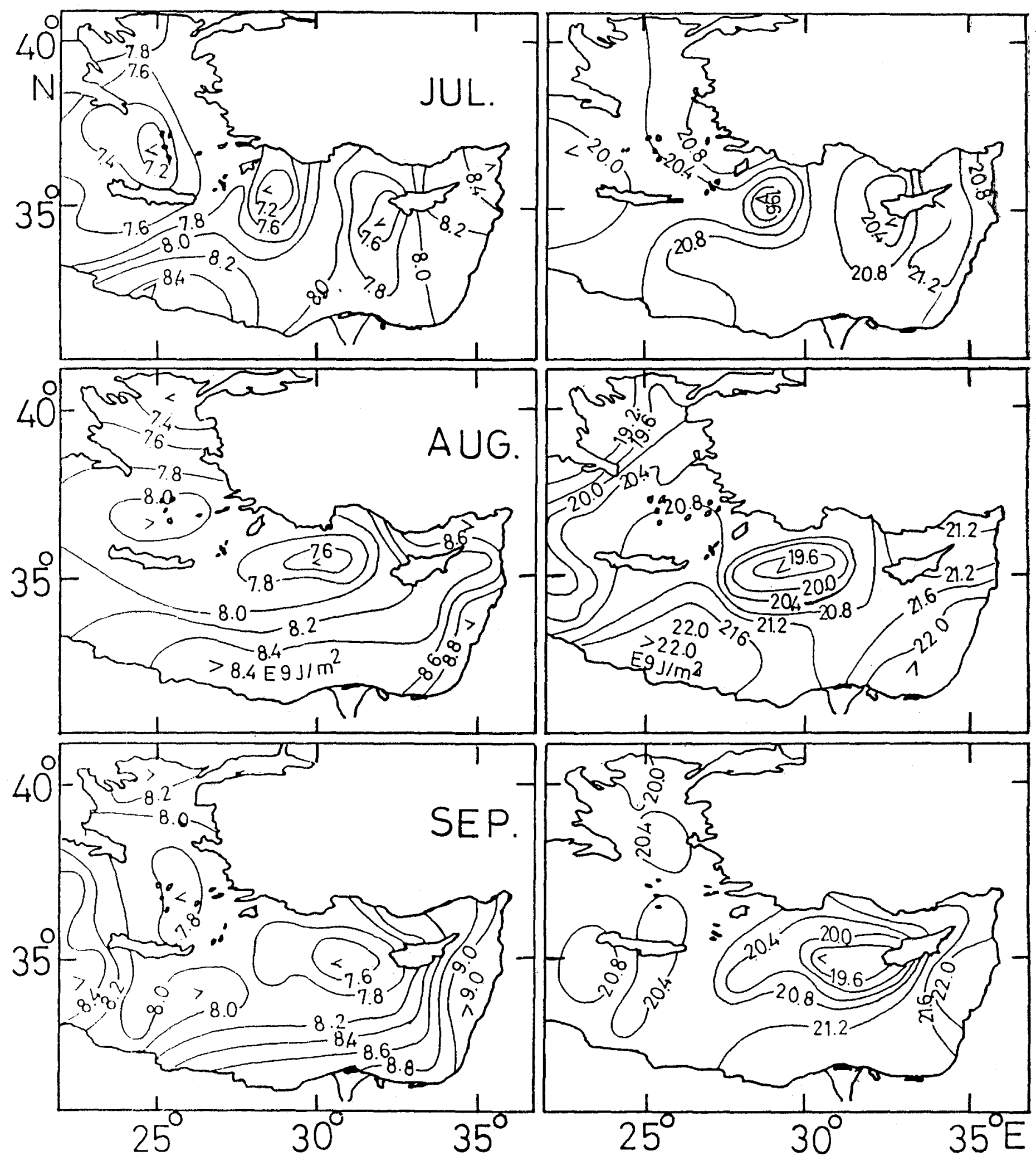

Fig. 1.c. Monthly distribution of heat storage in the upper $100 \mathrm{~m}$ (Left panel) and $300 \mathrm{~m}$ (Right panel) layers in Summer. 

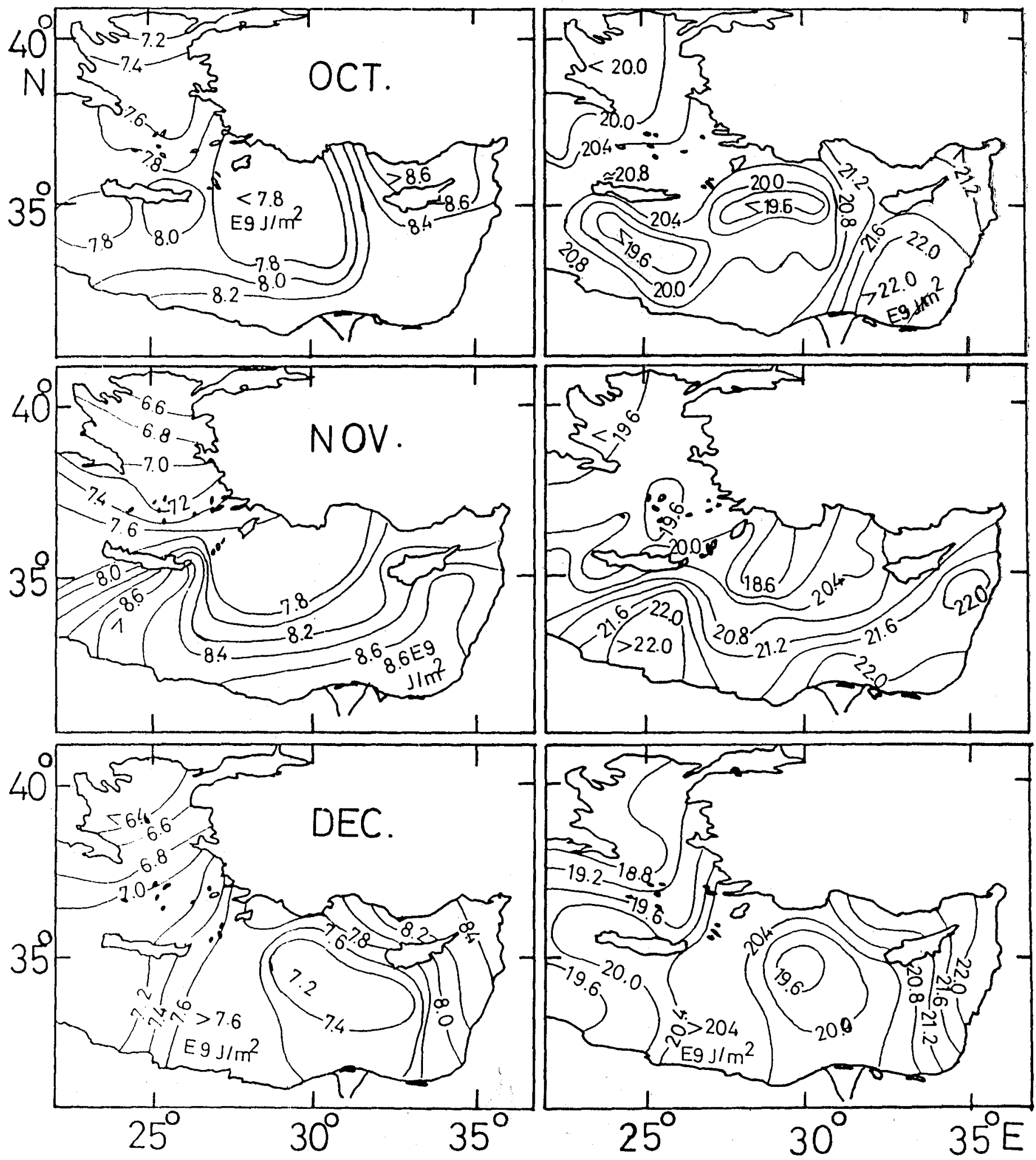

Fig. 1.d. Monthly distribution of heat storage in the upper 100m (Left panel) and $300 \mathrm{~m}$ (Right panel) layers in Autumn. 


\section{ANNUAL TREND OF MONTHLY MEAN HEAT STORAGE}

The annual trend of the monthly zonal mean heat storage in the two considered layers for the Levantine, Aegean and
In the upper $100 \mathrm{~m}$.

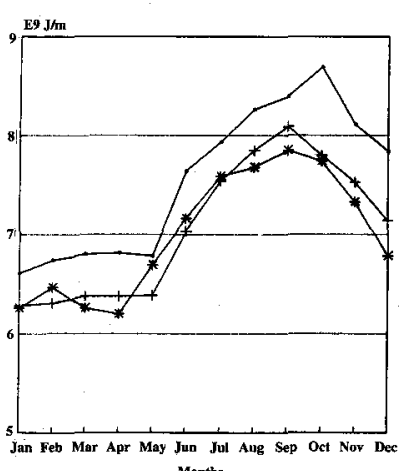

Months
In the upper $300 \mathrm{~m}$.

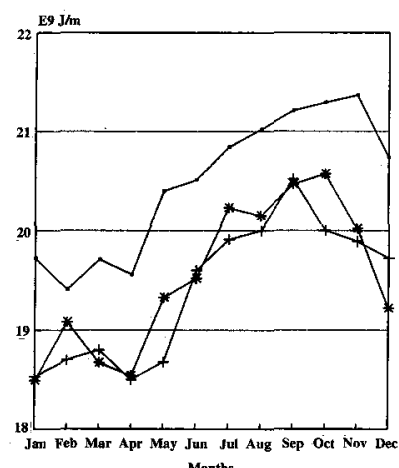

Months
--- Levantine, --- Ionian, --- Aegean Seas

Fig. 2. Monthly heat storage
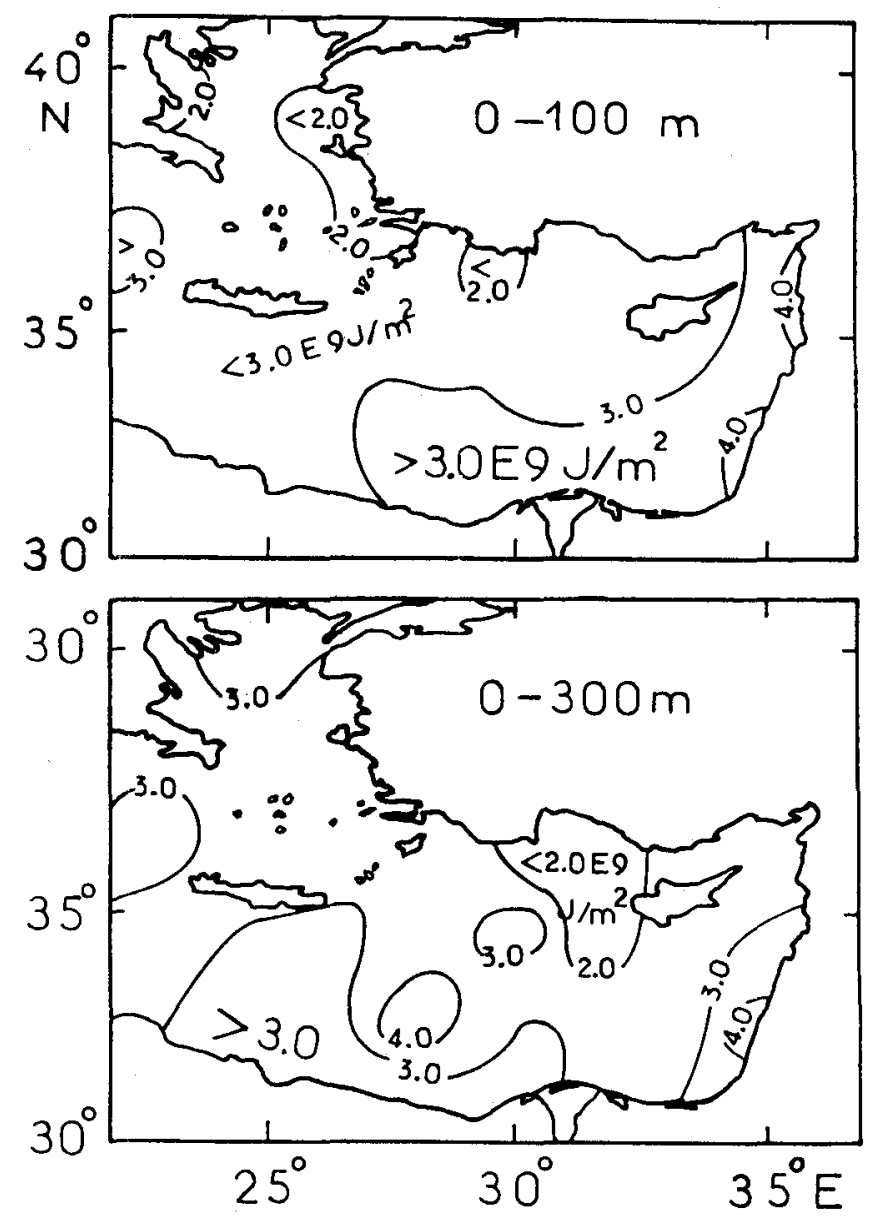

Fig. 3. Horizontal distribution of the amplitude of annual signal in the upper $100 \mathrm{~m}$ (upper panel) and $300 \mathrm{~m}$ (lower panel) layers.
Ionian Seas (Fig. 2) shows that, heat storage in both layers is higher in the Levantine Sea than in the Aegean or Ionian Seas due to the fact that the Levantine Basin lies at a lower latitude than the other two Basins. Moreover, the amplitude of annual zonal mean heat storage is greater, with about $6 \%$ more in the 0-100 m layer than in the 0-300 m layer in Levantine Sea, and with $12 \%$ and $25 \%$ more in $0-300 \mathrm{~m}$ layer than in the upper $100 \mathrm{~m}$ for the Ionian and Aegean Seas, respectively.

The sources of the heat, in the upper $100 \mathrm{~m}$ layer are mainly solar radiation through the surface and advection from the west by the north African current. Below the $100 \mathrm{~m}$, the source of heat is located in the north Levantine Basin, where vertical convection of heat within Rhodes cyclonic gyre, and subsequent west-ward advection (horizontally) occurs within the Intermediate water mass.

The monthly zonal mean heat storage in the upper $100 \mathrm{~m}$ layer ranges from $6.6 \mathrm{E} 9 \mathrm{~J} / \mathrm{m}^{2}$ in January to $8.7 \mathrm{E} 9 \mathrm{~J} / \mathrm{m}^{2}$ in October in the Levantine Basin. For the Ionian Sea, values range between 6.3 and $8.1 \mathrm{E} 9 \mathrm{~J} / \mathrm{m}^{2}$ in January and September, respectively. Similar values occur in the Aegean Sea, 6.2 and $7.9 \mathrm{E} 9 \mathrm{~J} / \mathrm{m}^{2}$ in April and September, respectively.

In the $300 \mathrm{~m}$ layer, the monthly zonal mean heat storage ranges between $19.4 \mathrm{E} 9 \mathrm{~J} / \mathrm{m}^{2}$ in February and $21.4 \mathrm{E} 9 \mathrm{~J} / \mathrm{m}^{2}$ in November for the Levantine Basin. In the Ionian Sea it varies from 18.5E9 J/m $\mathrm{m}^{2}$ in April to $20.5 \mathrm{E} 9 \mathrm{~J} / \mathrm{m}^{2}$ in September. In the Aegean Sea, it changes between $18.5 \mathrm{E} 9 \mathrm{~J} / \mathrm{m}^{2}$ in April and 20.6E9 J/m $\mathrm{m}^{2}$ in October.

In general, the heat storage and duration is greater in the Levantine Basin (Fig. 2).

\section{HORIZONTAL DISTRIBUTION OF THE ANNUAL SIGNALS}

Figure 3, illustrate the geographic distribution of annual signal for the $0-100$ and $0-300 \mathrm{~m}$ layers.

In the $0-100 \mathrm{~m}$ layer the amplitude of the annual signal is minimum (less than $2 \mathrm{E} \mathrm{J} / \mathrm{m}^{2}$ ) in the northern Levantine and eastern Aegean Seas. In the eastern and southern Levantine Basin, it is high (more than $3 \mathrm{E} 9 \mathrm{~J} / \mathrm{m}^{2}$ and may reach more than $4 \mathrm{E} 9 \mathrm{~J} / \mathrm{m}^{2}$ ) in the extreme eastern part of the area under study. The amplitude in the remaining area ranges between $2 \mathrm{E} 9 \mathrm{~J} / \mathrm{m}^{2}$ and $3 \mathrm{E} 9 \mathrm{~J} / \mathrm{m}^{2}$.

For the $0-300 \mathrm{~m}$ layer, the amplitude of annual signal is minimum (less than $2 \mathrm{E} 9 \mathrm{~J} / \mathrm{m}^{2}$ ) in the northern Levantine Basin, whereas it is higher than $3 E 9 \mathrm{~J} / \mathrm{m}^{2}$ in the south west and south east portions of the Levantine Basin and northern Aegean Seas.

There are two foci of maximum amplitude (more than 4E9 $\mathrm{J} / \mathrm{m}^{2}$ ) in the central south and southeast area of the Levantine Basin.

It should also be mentioned that, in the Levantine Basin, the region of the Rhodes cyclonic gyre is an area of maximum amplitude in the annual signal. Whereas, in the regions of Mersa - Matroh, in the south central, and Shikmona, in the southeast, anticyclonic warm core eddies (Brenner, 1989) characterize the maximum amplitude (more than $4 \mathrm{E} 9 \mathrm{~J} / \mathrm{m}^{2}$ ) area. 


\section{ACKNOWLEDGEMENT}

This work was partially supported by USAID in the Frame work of "Circulation in the Levantine Basin" project.

\section{REFERENCES}

Brenner, S., 1989. Structure and evolution of warm core eddies in the eastern Mediterranean Levantine Basin. J. GEOPHYS. RES. 94 (C9): 12593-12692.

Grillaki, D. and S. Piacsek, 1985. Numerical simulations of the circulation of the eastern Mediterranean, Report \#: AD-A170219; SACLANTCEN-SR-92:30 P.

Hopkins, T.X., 1983. Discussion of the Ionian and Levantine Seas, NATO Workshop on Atmospheric and Oceanic Circulation in the Mediterranean basin. NATO Workshop on Atmospheric and Oceanic Circulation in the Mediterranean Basin, Santa Teresa (Italy), 7 .Sep 1983: $42 \mathrm{p}$.
Korn, P. A., 1972. Rate of change of heat storage of the world ocean. J. of Physical Oceanography, 17.(4): 517-528.

Picco, P., 1990. Heat storage in the western mediterranean Seat. Rapp. Comm. int. Mer. Medit., 32, 1, 166.

Said, M. A., 1985. The sources of formation of the intermediate water masses in the Mediterranean Sea. Acta Adriat., 26(2): 191-201. 